\title{
Identifying Root Causes of Construction Accidents
}

\author{
By Tariq S. Abdelhamid,' Student Member, ASCE, and John G. Everett, ${ }^{2}$ Member, ASCE
}

\begin{abstract}
Construction accident investigation techniques and reporting systems identify what type of accidents occur and how they occurred. Unfortunately, they do not properly address why the accident occurred by identifying possible root causes, which is only possible by complementing these techniques with theories of accident causation and theories of human error. The uniqueness of the construction industry dictates the need to tailor many of the contemporary accident causation model: and human error theories. This paper presents an accident root causes tracing model (ARCTM) tailored to the needs of the construction indusiry. ARCTM proposes that accidents occur due to three root causes: (1) Failing to identify an unsafe condition that existed before an activity was started or that develuped after an activity wais started; (2) veciding to proceed with a worh activity after the worker identifies an existing unsafe condition; and (3) deciding to act unsafe regardless of initial conditions of the work environment. In addition, ARCTM emphasizes the need to determine how unsafe conditions exist before or develop after an activity is started and proposes that these unsafe conditions are due to four causes: (1) Management actions/inactions; (2) unsafe acts of worker or coworker; (3) non-human-related event(s); (4) an unsafe condition that is a natural part of the initial construction site conditions. Thus, ARCTM acknowledges the possible contribution of both management and labor to the accident process. This perspective helps in better explaining accidents on construction sites and in identifying areas where prevention efforts should be directed, so that labor and management may provide more effective measures for preventing accident occurrence.
\end{abstract}

\section{INTRODUCTION}

Construction work is hazardous work. The National Safety Council reports that in 1996 alone, 1,000 construction workers lost their lives at work and another 350,000 received disabling injuries. Construction accounted for only $5 \%$ of the United States' workforce but claimed a disproportionate $20 \%$ of all occupational fatalities and $9 \%$ of all disabling occupational injuries (Accident 1997).

A review of the literature on construction safety reveals that much research effort has been directed at examining accident records to categorize the most common types of accidents that occur to a specific trade, and how these accidents happen (Fullman 1984; Goldsmith 1987; Culver et al. 1990, 1992; Davies and Tomasin 1990; La Bette 1990; MacCollum 1990; Rietze 1990; Helander 1991; Peyton and Rubio 1991; Hinze 1997). These studies reveal many important trends about construction accidents within a construction trade and also reveal the most hazardous accidents. For example, Helander (1991) reported that carpenters tend to have more finger accidents compared to masons who suffer more from overexertion injuries. Culver et al. (1990) and others reported that most fatalities in construction occur due to falls.

Despite the importance of such study findings to guide accident prevention plans, it is our assertion that construction accident investigations stop at a premature level or are missing important steps to identify the root causes of accidents. As summarized by Brown (1995), "Accident reporting is a means to an end, not an end in itself." In other words, the answers that accident investigations provide for the "what" and "how" questions, should be used to determine the factors that contributed to the accident causation (i.e., why the accident occurred). Brown (1995) argued convincingly that accident investigation techniques should be firmly based on theories of

'Grad. Student Res. Asst., Civ. and Envir. Engrg., Univ. of Michigan, 1340 G. G. Brown. Ann Arbor, MI 48109-2125.

${ }^{2}$ Asst. Prof. of Civ. and Envir. Engrg., Univ. of Michigan. 2353 G. G. Brown, Ann Arbor, MI

Note. Discussion open until July 1, 2000. To extend the closing date one month. a written request inust be filed with the ASCE Munager of Journals. The manuscript for this paner was submitted for 1eview and possible publication on October 27, 1998. This paper is part of the Journal of Construction Engineering and Management, Vol. 126, No. 1, Jainuary/February, 2000. CASCE, ISSN 0733-9634/00/0001-(0052-0060/ $\$ 8 .(K)+\$ .50$ per page. Paper No. 19526. accident causation and human error, which would result in a better understanding of the relation between the "antecedent human behavior" and the accident at a level enabling the root causes of the accident to be determined. Consequently, prevention efforts could be directed at the root causes of accidents and not at symptoms, leading to more effective accident prevention.

The objective of this paper is to introduce an accident root causes tracing model (ARCTM). The goal is to complement existing construction accident investigation techniques with contemporary accident causation and human error theories. This would provide management with a simple and easy to use template for systematically and rapidly determining why an accident occurred so that more effective measures for preventing accident reoccurrence can be implemented. Three reallife road-construction accidents will be presented as they were investigated, and the use of the suggested new complementary model will be described.

\section{OVERVIEW}

The following is a review of the most prominent and widely disseminated accident causation models and human error theories that are of primary interest to this paper. For the most part this review will be described without an attempt at detailed critique. Before proceeding, the reader's attention is brought to the fact that some models were developed due to a brief surge of interest to a specific theory or concept. Such models seldom show up in contemporary literature on occupational accidents. Some models are not of primary interest to this research but are only provided so that the reader may appreciate the diversity and complexity of various existing models. This should explain the gaps or discontinuation in the narration.

\section{Accident Causation Models}

Many researchers have tried to understand accidents in industrial applications by introducing accident causation models. In general, the overall objective of these models is to provide tcols for better industrial accident prevention programs. Accident prevention has been defined by Heinrich et al. (1980) as "An integrated program, a series of coordinated activities, directed to the control of unsafe personal performance and unsafe mechanical conditions, and based on certain knowl- 
edge, attitudes, and abilities." Other terms have emerged that are synonymous with accident prevention such as loss prevention, loss control, total loss control, safety management, incidence loss control, among many others.

\section{Domino Tileory}

In 1930, research in accident causation theory was pioneered by Heinrich. Heinrich (1959) discussed accident causation theory, the interaction between man and machine, the relation between severicy and frequency, the reasons for unsafe acts, the management role in accident prevention, the costs of accidents, and finally the effect of safety on efficiency. In addition, Heinrich developed the domino theory (model) of causation, in which an accident is presented as one of five factors in a sequence that results in an injury. The label was chosen to graphically illustrate the sequentiality of events Heinrich believed to exist prior to and after the occurrence of accidents. In addition, the name was intuitively appealing because the behavior of the factors involved was similar to the toppling of dominoes when disrupted: if one falls (occurs), the others will too.

Heinrich had five dominoes in his model: ancestry and social environment, fault of person, unsafe act and/or mechanical or physical hazard, accidents, and injury. This five-domino model suggested that through inherited or acquired undesirable traits, people may commit unsafe acts or cause the existence of mechanical or physical hazards, which in turn cause injurious accidents. Heinrich defined an accident as follows: "An accident is an unplanned and uncontrolled event in which the action or reaction of an object, substance, person, or radiation results in personal injury or the probability thereof." The work of Heinrich can be summarized in two points: people are the fundamental reason behind accidents; and management - having the ability - is responsible for the prevention of accidents (Petersen 1982).

Some of Heinrich's views were criticized for oversimplifying the control of human behavior in causing accidents and for some statistics he gave on the contribution of unsafe acts versus unsafe conditions (Zeller 1986). Nevertheless, his work was the foundation for many others. Over the years the domino theory has been updated with an emphasis on management as a primary cause in accidents, and the resulting models were labeled as management models or updated domino models. Management models hold management responsible for causing accidents, and the models try to identify failures in the management system. Examples of these models are the updated domino sequence (Bird 1974), the Adams updated sequence (Adams 1976), and the Weaver updated dominoes (Weaver 1971). Two other accident causation models that are management based but not domino based are the stair step model (Douglas and Crowe 1976) and the multiple causation model (Petersen 1971). From these, the multiple causation model (Petersen 1971) will be briefly described.

\section{Multiple Causation Model}

Petersen introduced this management non-domino-based model in his book Technique of Safety Management (Petersen 1971). Petersen believed that many contributing factors, causes, and subcauses are the main culprits in an accident scenario and, hence, the model concept and name "multiple causation." Under the concept of multiple causation, the factors combine together in random fashion, causing accidents. Petersen maintained that these are the factors to be targeted in accident investigation.

Petersen viewed his concept as not exhibiting the narrow interpretation exhibited by the domino theory. To explain his concept, Petersen provided an example of a common accident scenario, that of a man falling off a defective stepladder. Petersen believed that by using present investigation forms, only one act (climbing a defective ladder) and/or one condition (a! defective ladder) would be identified. The correction to the problem would be to get rid of the defective ladder. This would be the typical s!mpervisor's investigation if the domino theory was used.

Petersen claimed that by using multiple causation questions, the surrounding factors to the "incident" (Petersen uses the word accident and incident interchangeably) would be revealed. Applicable questions to the stepladder accident would be: why the defective ladder was not found in normal inspections; why the supervisor allowed its use; whether the injured employee knew that he/sine shouid not usc the ladder; whether the employee was properly trained; whether the employee was reminded that the ladder was defective; whether the supervisor examined the job first. Petersen believed that the answers to these and other questions would lead to improved inspection procedures, improved training, better definition of responsibilities, and prejob planning by supervisors.

Petersen also asserted that trying to find the unsafe act or the condition is dealing only at the symptomatic level, because the act or condition may be the "proximate cause," but invariably it is not the "root cause." As most others did, Petersen emphasized that root causes must be found to have permanent improvement. He indicated that root causes often relate to the management system and may be due to management policies, procedures, supervision, effectiveness, training, etc.

\section{Human Error Theories}

Human error theories are best captured in behavior models and human factor models. Behavior models picture workers as being the main cause of accidents. This approach studies the tendency of humans to make errors under various situations and environmental conditions, with the blame mostly falling on the human (unsafe) characteristics only. As defined by Rigby (1970), human error is "any one set of human actions that exceed some limit of acceptability." Many researchers have devoted great time and effort to defining and categorizing human error [e.g., Rock et al. (1966), Recht (1970), Norman (1981), Petersen (1982), McClay (1989), DeJoy (1990), and Reason (1990)].

Similar to behavioral models, the human factors approach holds that human error is the main cause of accidents. However, the blame does not fall on the human unsafe characteristics alone but also on the design of workplace and tasks that do not consider human limitations and may have harmful effects. In other words, the overall objective of the human factors approach is to arrive at better designed tasks, tools, and workplaces, while acknowledging the limitations of humans physical and psychological capabilities. This approach stems from the relatively new engineering field known as human factors engineering.

\section{Behavior Models}

The foundation of most behavior models is the accident proneness theory (Accident 1983). This theory assumes that there are permanent characteristics in a person that make him or her more likely to have an accident. The thenry was supported by the simple fact that when considering population accident statistics, the majority of people have no accidents, a relatively small percentage have one accident, and a very smali percentage have multiple accidents. Therefore, this small group must possess personal characteristics that make them more prone to accidents (Klumb 1995). This concept has been accepted by many researchers; however, there are a number 
of arguments against it which are documented in Heinrich et al. (1980).

Many behavior models have been developed to explain the reason for accident repeaters. These models include the goals freelom alertness theory (Kerr 1957), and the motivation rcward satisfaction modei (Petersen 1975). [For other bchaviorai models, see Krause et al. (1984), Hoyos and Zimolong (1988), Wagenaar et al. (1990), Dwyer and Raftery (1991), Heath (1991), Friend and Khon (1992), and Krause and Russell (1994).]

\section{Human Factor Models}

The work of Cooper and Volard (1978) summarize the common and basic ideas to the field of human factors engineering. They stated that extreme environment characteristics and overload of human capabilities (both physical and psychological) are factors that contribute to accidents and to human error. Examples of human factor models include the Ferrel theory (Ferrel 1977), the human-error causation model (Petersen 1982), the McClay model (McClay 1989), and the DeJoy model (DeJoy 1990).

\section{Ferrel Theory}

One of the most important theories developed in the area of human factor models is that by Ferrel [as referenced in Heimrich et al. (1980)]. Similar to the multiple causation theory, the Ferrel theory attributes accidents to a causal chain of which human error plays a significant role. According to the theory, human errors are due to three situations: (1) Overload, which is the mismatch of a human's capacity and the load to which he/she is subjected in a motivational and arousal state; (2) incorrect response by the person in the situation that is due to a basic incompatibility to which he/she is subjected; and (3) an improper activity that he/she performs either because he/she didn't know any better or because he/she deliberately took a risk. The emphasis in this model is on overload and incompatibility only, which are the central points in most human factor models.

\section{ARCTM: CONSTRUCTION MODEL}

In the following sections, ARCTM will be introduced. ARCTM represents the further development and synthesis of many of the previously mentioned models. Many important features of the model have been taken from the work of Heinrich (1959), Petersen (1971), Bird (1974), Ferrel [as referenced in Heimrich et al. (1980)], and Petersen (1982).

In developing ARCTM, the main purpose was to provide an investigator with a model to easily identify root causes of accidents versus developing a model with abstract ideas and complicated technical occupational safety jargon and confusing definitions for relatively clear terms such as accident and injury. ARCTM attempts to direct the attention of the investigator to the conditions that existed at the time of the accident and antecedent human behavior.

\section{ARCTM and Accidents}

The main concept proposed in ARCTM is that an occupational accident will occur due to one or more of the following three root causes:

1. Failing to identify an unsafe condition that existed before an activity was started or that developed after an activity was started

2. Deciding to proceed with a work activity after the worker identifies an existing unsafe condition
3. Deciding to act unsafe regardless of initial conditions of the work environment

Clearly, these root causes develop becausc of different reasons, and also point to different issues that should be considercd for correcive actions. ARCTM was designed to guide the investigator through a series of questions and possible answers to identify a root cause for why the accident occurred and to investigate how the root cause developed and how it could be eliminated.

Because "unsafe conditions," "worker response to unsafe conditions," and "worker unsafe acts" are comerstones of ARCTM, they will be discussed first in the following sections befure the use of ARCTM is explained and demonstrated by considering real-life accident scenarios.

\section{Unsafe Conditions}

An unsafe condition is a condition in which the physical layout of the workplace or work location, the status of tools, equipment, and/or material are in violation of contemporary safety standards. Examples of unsafe conditions include opensided floors, defective ladders, improperly constructed scaffolds, protruding ends of reinforcing rods, protruding nails and wire ties, unshored trenches, defective equipment, overloaded tools or equipment, unprotected explosive material, ungrounded electrical tools, flying materials, etc.

Unsafe conditions are mentioned in almost every accident causation model as a main cause of an accident. This is still the case in ARCTM; however, two different types of unsafe conditions are distinguished based on when they occurred in the work sequence, as well as who caused them to exist or develop. First, an unsafe condition may exist before an activity is started. Second, an unsafe condition may develop after an activity is started. ARCTM proposes that these two types of unsafe conditions are due to one of the following causes: (1) Management actions/inactions; (2) worker or coworker unsafe acts; (3) nonhuman related event(s); and (4) unsafe condition is a natural part of the initial construction site conditions.

For example, management may fail to provide proper or adequate personal protective equipment; fail to maintain or safeguard tools and equipment; and/or violate workplace standards by allowing slippery floors, insufficient ventilation, poor housekeeping, etc. Moreover, management may unintentionally request workers to perform tasks that exceed human capabilities or that violate human factors, ergonomics, and/or industrial hygiene principles. This often leads to overexertion injuries and illnesses.

A worker or coworker may be inexperienced or new on site, or may choose to act unsafe, all of which may lead to unsafe conditions for other workers. Examples of unsafe acts leading to unsafe conditions include removing machine safeguards, working while intoxicated, working with insufficient sleep, sabotaging equipment, disregarding housekeeping rules, unauthorized operation of equipment, horseplay, etc.

Non-human-related events that may lead to unsafe conditions include systems, equipment or tool failures, earthquakes, storms, etc. Unsafe conditions that are a natural part of the initial construction site conditions are used in ARCTM to account for a unique type of unsafe conditions in the construction industry. Examples of these conditions include uneven terrain, concealed ditches, scattered metallic or nonmetallic materials, etc. These unsafe conditions are usually renıoved during initial site preparations.

\section{Worker Response to Unsafe Conditions}

In addition to distinguishing between types of unsafe conditions and who is responsible for them, ARCTM emphasizes 
the need to consider how workers respond to or are affected by an unsafe condition. Basically, when an unsafe condition exists before or develops after a worker starts an activity, the worker either fails or succeeds in identifying it.

If the worker fails to identify the unsafe condition, this ineaus there was no considcration of any risks, and the worker does not recngnize the potential hazards. If the worker identifies the unsafe condition, an evaluation of risk must be made. The worker's decision is either to act safe and discontinue the work until the unsafe condition is corrected or take a chance (act unsafe) and coutinue working. The reasons behind failing to identify the unsafe condition or the decision to act unsafe after identifying an unsafe condition should be thoroughly investigated by management.

It should be noted that some unsafe conditions may never be possible to identify by a worker. Examples of such conditions are non-human-related events, or conditions where there are human factors violations. Human factors violations are typically responsible for such injuries as overexertion, cumulative trauma disorders, fatigue, toxic poisoning, mental disorders, etc. Moreover, in many industries, particularly in construction, a worker may simply have no previous experience with the task being performed because it is completely new.

\section{Worker Unsafe Acts}

A worker may commit unsafe acts regardless of the initial conditions of the work (i.e., whether the condition was safe or unsafe). Example of worker unsafe acts include the decision to proceed with work in unsafe conditions, disregarding standard safety procedures such as not wearing a hard hat or safety glasses, working while intoxicated, working with insufficient sleep, etc. Therefore, the need to investigate why workers act unsafe is also emphasized in ARCTM.

\section{Accident Investigations Using ARCTM}

After a preliminary accident investigation using the organization's accident investigation and reporting tool, the investigator should further investigate the accident using ARCTM. ARCTM is organized in a flowchart structure as shown in Fig. 1. It is important to recall here that an accident occurs due to one or more of the three root causes suggested in ARCTM, as mentioned earlier.

These root causes are investigated in ARCTM through a series of questions and possible answers that help the investigator determine how the root cause developed. As shown in Fig. 1, a number inside brackets has followed each possible question/answer. Each number signifies a certain issue that needs to be addressed or corrected to prevent accident reoccurrence. The numbers [1], [2], and [3] represent a worker training problem, a worker attitude problem, and a management procedures problem, respectively. These problems should not be confused with the root causes of the accident but point both labor and management to find ways to prevent the accident's reoccurrence. It is also important to note that an investigator should add, when needed, to the possible questions/ answers that ARCTM provides and not restrict his/her attention to them. Using ARCTM consists of the following steps:

Step 1. Determining whether there was one or more unsafe conditions that faced the worker involved in the accident (before or after starting the activity). If a worker was faced by an unsafe condition (before or after starting the activity), it should be determined how the unsafe condition existed or develuped, by addressing the questions shown in Fig. 1. As discussed earlier, ARCTM proposes that existing or developing unsafe conditions are due to four causes: management actions/inac- tions; worker or coworker unsafe acts; non-human-related events; and/or unsafe condition that is natural part of the initial construction site conditions (i.e., preexisting unsafe conditions on the construction site)

- Management actions'inaciions resulted in the unsafe condition:

- The investigator should determine why the unsafe condition was not identified and removed by management, and who is responsible for such tasks. The number [3] after each of the quesiions in Fig. 1 indicates that there is a problem with management procedures, which requires further investigation and correction.

- Worker or coworker unsate acts resulted in the unsafe condition:

- The investigator should determine if the unsafe act was caused by social, peer, or management pressure. If social or peer pressure led to the unsafe act, this points out a worker attitude problem. If management pressure led to the unsafe act, this points out a problem with management procedures.

- The investigator should determine whether the (co)worker knew the correct procedure of performing the work. If the worker did not, this points out a worker training problem. If the worker did, this points out a worker attitude problem.

-The investigator should also determine if the (co)worker has always/occasionally acted unsafe while performing work. If the worker did, this points out a problem with management procedures because management should have measures in place to detect and discourage worker unsafe acts as they occur. If the worker committed the unsafe act for the first time, the previous questions will reveal the reason behind the unsafe act.

- Non-human-related event or a pre-existing unsafe condition on the construction site was the cause of the unsafe condition:

-The investigator should determine whether it was possible for management or workers to identify such an event or condition. If the investigator has reason to believe that it was possible to identify such an event or condition, this points out a problem with both worker training and management procedures. If it was impossible for management or workers to identify such an event or condition, then the accident would have been truly unavoidable.

Step 2. If a worker was faced by an unsafe condition (before or after starting the activity), it should be determined whether the worker had identified the unsafe condition.

- If the worker did not identify the unsafe condition, the investigator should determine the reasons behind this failure by addressing the questions shown in Fig. 1:

- The investigator should determine if the worker made wrong assumptions about the condition, was unable to assess the condition because the task was new, or had insufficient knowledge to identify unsafe conditions related to his/her task. All these reasons for failing to identify the unsafe condition indicate a problem with worker training.

-The investigator should consider if the worker was informed that the condition was safe. In such a case, the investigator should determine who informed the worker the condition was safe (a coworker or management), and why the informant regarded the condition as safe. If a coworker informed the worker and de- 


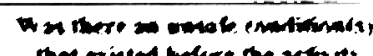

was started, or inat de cloped aller

the activity was started?

Yes

How did this unsa fe condition(s) exist

or develop?

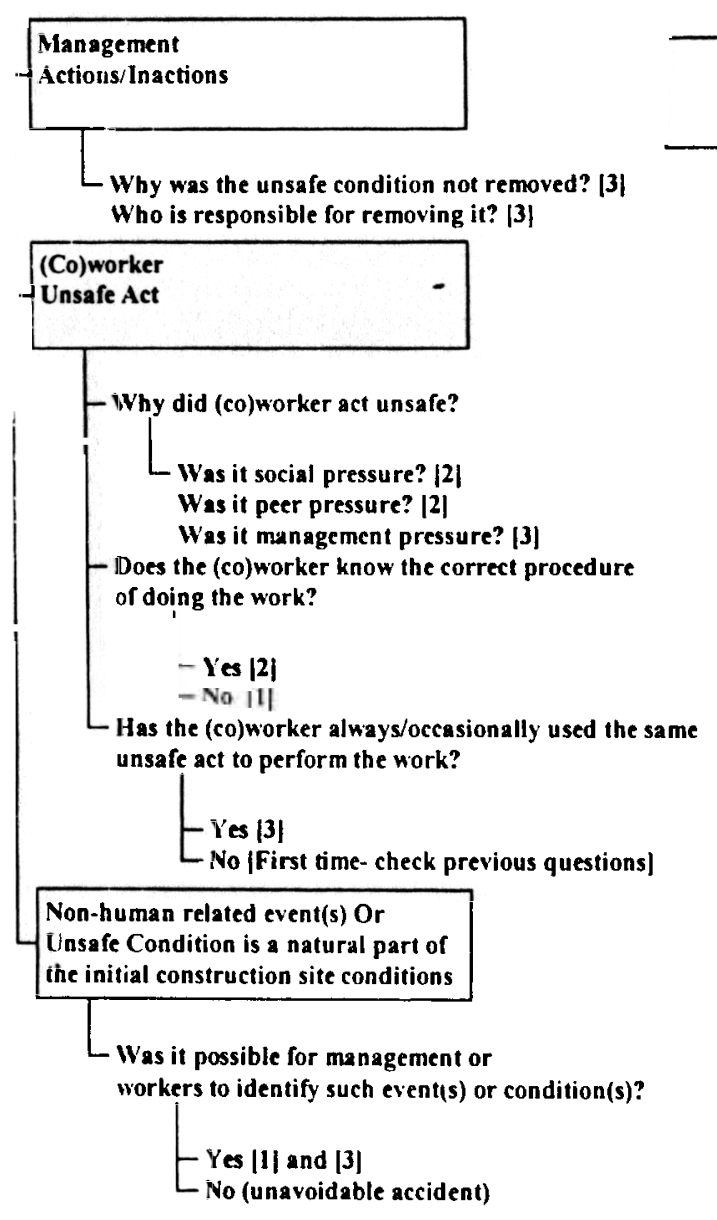

Did the worker identify
the unsafe condition(s)?

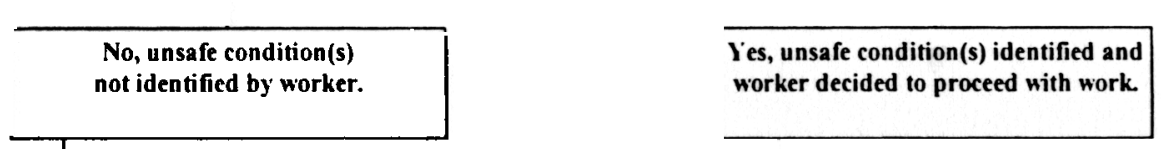

Why did the worker fail to

identify the unsafe condition(s)?

- Worker made wrong

assumptions about condition [1]

Inable to assess condition

because condition is new [1]

- Insufficient knowledge to

identify unsafe condition(s) [1]

- Worker was informed

that condition is safe

L

Who informed the worker and why was the condition regarded as safe?

ins the

LW'as it Co-worker? [1] or [2]

W'as it Mlanagement? [3]

Worker did not follow correct

procedures in doing work

- Does the worker know the

correct procedure of doing

the work?

- ies [2]

$$
\begin{aligned}
& \text { - Yes [2] } \\
& \text { No [1] }
\end{aligned}
$$

Has the worker always/occasionally used

the same procedure to perform

the work?

$$
\text { - Yes [3] }
$$

No [First time- check previous questions|

correct procedure of doing
-W'hy did the worker decide to proceed?

I

- Was it social pressure? [2]

Was it peer pressure? [2]

Was it management pressure? 3

Did the - orker fail to identify all

attributes to the situation? [1]

Did the worker think (s)he couls

still do the job? $|2|$

- Does the worker know the

the work?

- iss 12

- llas the worker al ways/occasionally.

proceeded with the work despite

$$
\text { Lies [3] }
$$

Eo [First time- check previous ģuestions]

Issues to consider as corrective actions:

[1] Worker Training

[2] Worker Attitude

[3] Management Procedures Was it peer pressure? [2]

FIG. 1. Accident Root Causes Tracing Model (ARCTM)

Did the worker commil an unsafe act?

- No. (Re-check unsafe cconditions)

-Why did the worker act unsafe?

Was it social pressure? $|2|$

Was it managemient pressure? \{\}\}

- Does the worker know the Drocedure of doing the work?

$$
\text { L ies [2] }
$$

- Has the worker alwavs/occasionally used the same unsafe act to perform the nork?

$-\operatorname{sics}|3|$

check previous questions| 
pending on why the coworker regarded the condition as safe, there could be a problem with either worker Iraining or worker attitude. If management informed the worker, this points out a problem with management procedures.

- The investigator should also determine if the worker did not follow correct procedures in performing the work (i.e., if there were necessary steps that the worker had to perform to check the safety of the condition he/ she is working in). If the worker failed to follow these procedures, the investig:tor should determine whether the worker knew these procedures. If the worker did not, this poinis out a worker training problem. if the worker did, this points oui a worker attitide problein.

- The investigator should also determine if the worker has always/occasionally used the same incorrect procedure in performing the work. If the worker did, this indicates a problem with management procedures because management should have measures in place to detect such incorrect procedures. If the worker used an incorrect procedure in performing the work for the first time, the previous questions will reveal the reason for not following the correct procedure.

- If the worker identified the unsafe condition and decided to proceed with the activity, then the investigator should determine the reasons behind the incorrect decision by addressing the questions shown in Fig. 1:

- The investigator should determine if the worker considered that taking a risk was necessary or forced on him or her because of social, peer, or management pressures. If social or peer pressure led to the decision, this points out a worker attitude problem. If management pressure led to the decision, this points out a problem with management procedures.

- The investigator should determine if the worker failed to identify all attributes to the situation. If the worker failed in doing so, this points out a worker training problem.

-The investigator should determine if the worker thought he/she could still perform the job safely. If the worker did, this points out a worker attitude problem.

- The investigator should also determine whether the worker knew the correct procedure of performing the work. If the worker did not, this points out a worker training problem. If the worker did, this points out a worker attitude problem.

-The investigator should determine if the worker has always/occasionally proceeded with the work despite identifying the unsafe conditions. If the worker did, this indicates a problem with management procedures because management should have measures in place to detect and discourage worker unsafe acts as they occur. If the worker proceeded with work despite identifying the unsafe conditions for the first time, the previous questions will reveal the reason behind the decision to proceed.

Step 3. If there were no unsafe condition(s) that faced the worker involved in the accident (before or after starting the activity), the investigator should determine whether the worker acted unsafe or not.

If there was no unsafe act on the worker's part, the investigator should reconsider the unsafe conditions surrounding the accident again by revisiting step number 1 above.

If a worker acted unsafe, the investigator should determine the reasons behind this behavior by addressing the questions shown in Fig. 1:
- The investigator should determine if the unsafe act was caused by social, peer, or management pressure. If social or peer pressure led to the unsafe act, this points out a worker attitude problem. If management pressure led to the unsafe act, this points out a problum with management procedurs.

-The investigator should determine whether the worker knew the correct procedure of performing the work. If the worker did not, this points out a worker training problem. If the worker did, this points out a worker attitude problem.

- The investigator should determine if the worker has always/occasionally acted unsafe while perfermilis work. If the worker did, this points out a problem with management procedures because management should have measures in place to detect and discourage worker unsafe acts as they occur. If the worker committed the unsafe act for the first time, the previous questions will reveal the reason behind the unsafe act.

\section{Examples}

To illustrate how ARCTM may be used to further investigate accidents, three accidents involving highway construction workers were selected from accident reports obtained from the Michigan Department of Transportation (MDOT). Occupational injury cases are reported on the Accident Investigation Report form developed by MDOT. The form is divided into six sections that have to be completed by the supervisor or investigator. These six sections are the personal information section, the Michigan Occupational Safety and Health Administration information section, the loss control-narrative section, the cause of accident section, the corrective action section, and the investigated by section. The total number of questions to be answered by the investigator is 51 .

In the loss control-narrative section, the information collected about the accident include road surface conditions, nature of the injury or illness (e.g., cut, burn, fracture, electric shock, skin irritation, etc.), part of body injured, source of personal injury (e.g., hand tools, machinery, surface, vehicle, etc.), type of accident (e.g., struck against, caught in, caught under, contact with chemical, etc.), activity the injured was engaged in (e.g., material handling, operating equipment, administrative, horseplay, etc.), an account of the events of accident, and a description of injury/illness/property damage.

In the cause of accident section the following questions are completed:

- Cause factors such as unsafe acts and/or unsafe condi tions, which are chosen from Table 1.

TABLE 1. Possible Causes of Accidents (Adapted from MDOT's Accident Investigation Report)

\begin{tabular}{|c|c|}
\hline $\begin{array}{c}\text { Unsafe acts - human factors } \\
\text { (1) }\end{array}$ & $\begin{array}{l}\text { Unsafe conditions - physical factors } \\
\qquad \text { (2) }\end{array}$ \\
\hline $\begin{array}{l}\text { Failed to secure and warn } \\
\text { Failed to wear personal protective } \\
\text { equipment }\end{array}$ & $\begin{array}{l}\text { Defects of accident source } \\
\text { Dress or apparel hasard }\end{array}$ \\
\hline Horseplay & Environmental hazan! \\
\hline Operated equipment without uthority & Fire hazard \\
\hline Operated at unsafe speed & Hazardous arrangement \\
\hline Personal factor & Hazardous method \\
\hline Remove safety device & Housekeeping hazard \\
\hline Serviced moving, energized squipment & Improper assignunent of personnel \\
\hline Teok unsate position or posture & Inadequately guardest \\
\hline Used defective tool or equipment & Public hayari \\
\hline Other unsafe action--specify & $\begin{array}{l}\text { Other unsaic conditionts - physical fa } \\
\text { tors }\end{array}$ \\
\hline $\begin{array}{l}\text { Unsafe act of another person(s) } \\
\text { Discegard known prescrited proce- } \\
\text { slures }\end{array}$ & Undeternined \\
\hline
\end{tabular}


- Opinion of major factor behind accident. The investigator has a choice of the following: inadequate supervision, inadequate training, inadequate planning, employee error, accident beyond control, other factors (should be specifieci), and undetermined.

The following is a summary of the original findings in three accidents selected using information from the loss control-narrative section, the cause of accident section, and the corrective action section only. Using the same information that was available to the investigator aidd using ARCTMi, the same accidents were further investigated to complement the initial investigations with possible questions tirat may lead to the root cduses of the accidents. The intention in applying ARCTM to these particular scenarios is to show that certain questions, which may add additional insight, are not addressed using the conventional accident investigation techniques. No attempt was made to find answers to the questions posed by ARCTM as this represented a rather sensitive issue to both the injured employees and MDOT.

\section{Accident No. 1}

The worker in this accident bruised his elbow as a result of a limb flipping from a brush chipper he was using. The investigator indicated the cause of the accident is "took unsafe position or posture" and "unsafe condition (brusher too fast)," and attributed the major cause of the injury to "other factor (unsafe brush chipper)." The investigator suggested that the brush chipper must be replaced as soon as possible because it is causing limbs to jerk, and he noted that a request had been made previously for the same problem and management had promised an immediate replacement.

Considering the first question posed by ARCTM regarding the existence of an unsafe condition before an activity is started or the development of an unsafe condition after an activity is started, it is apparent that there was an existing unsafe condition (the malfunctioning brush chipper), and the worker did identify the unsafe condition but decided to proceed with the work (determined from the narrative of the accident). The investigator should investigate the following questions:

1. How did the unsafe condition exist?

- Apparently, management actions/inactions is the reason for the unsafe condition to exist (the malfunctioning brush chipper). In fact a request had been made to management to replace the malfunctioning brush chipper prior to the accident but nothing was done. These facts point out a problem with management procedures, which needs to be further investigated. The investigator should also determine why this unsafe condition was not removed and who was responsible for removing it.

2. Why did the worker decide to proceed with the work despite identifying the existing unsafe condition?

- The worker indicated that he had to perform the work and that he could not wait for the new brush chipper to come in. This is most likely management pressure, which indicates a problem with management procedures.

3. Does the worker know the correct procedure of doing the work?

4. Has the worker always/occasionally proceeded with the work despite identifying unsafe conditions?

- Yes. The worker has been using the malfunctioning brush chipper since the request for replacing :vas filed. Because the worker was under management pressure, the investigator should address management proce dures to correct this problem.

\section{Accident No. 2}

The worke in this accident injured an eye (forcign body in eye) while replacing a burned electric board, which disintegrated causing minute particles to enter his eyes, despite his wearing safety glasses.

The investigator determined that the cause factor in this accident was "failed to wear personal protective equipment" and attributed the accident to "employee error." As a corrective action, the worker was instructed to wear safety goggles, which the worker indicated he knew that he should have.

Considering the first question posed by ARCTM regarding the existence of an unsafe condition before an activity is started or the development of an unsafe condition after an activity is started, it is apparent that there were no unsafe conditions of either type. This leads to considering whether the worker had committed an unsafe act, which in fact he did by not wearing the safety goggles. In this case the investigator should determine the following:

1. Why the worker acted unsafe?

2. Does the worker know the correct procedure of performing the work?

- Yes. The worker did acknowledge that he should have worn the safety goggles. The investigator should address worker attitude as an issue to correct this problem.

3. Has the worker always/occasionally used the same unsafe act in performing the work?

\section{Accident No. 3}

The worker in this accident strained his hand tendons while scaling bridge piers using a $1.35-\mathrm{kg}$ wedge pein hammer. The investigator indicated the cause of the accident is "undetermined" and attributed the major cause of the injury to "inadequate planning." No corrective actions were suggested.

Considering the first question posed by ARCTM regarding the existence of an unsafe condition before an activity is started or the development of an unsafe condition after an activity is started, it is apparent that there were no unsafe conditions of either type. This leads to considering whether the worker had committed an unsafe act. Surprisingly, the answer is no, and the investigator should reconsider the unsafe conditions question again.

Let us assume that there was an unsafe condition that existed before the worker started the work, and for the accident described, the only plausible unsafe condition under ARCTM is a violation of human factors, which the worker failed to identify. The investigator should investigate the following questions:

1. How did the unsafe condition exist or develop?

- It is obvious that the unsafe condition in this accident did not exist because of a coworker unsafe act, or because of a non-human-related event, or because the unsafe condition was a natural part of the construction site conditions. The only reason left is management actions/inactions. Unfortunately, despite the increased awareness of the importance of ergonomics in construction, there are no regulations or mandates that require construction management to perform ergonomic analyses of construction work. Thus, the investigator in this case would be faced with quite a dilemma in identifying management as a cause for this unsafe condition. It is important to note here that even though 
hammers of the type and weight used by the worker in this accident are common in construction, the repetitive use of such tools may lead to overexertion injuries. Recent research indicates that overexertion injuries are not necessarily a result of a sudden, brief, and/or forceful exertion, but they could also result from repetitive, nonforceful exertion that gradually inflect "microinjuries" in the tissues and tendons at the joints, eventually leading to a major injury (Chaffin and Andersson 1991).

2. Why the worker failed to ideniify this existing unsafe condition?

- In this case, the worker has insufficient knowledge to identify unsafe cunditions caused by a human factors violation. This points out a worker training problem.

3. Does the worker know the correct procedure of doing the work?

4. Has the worker always/occasionally proceeded with the work despite identifying unsafe conditions?

- Questions 3 and 4 would be irrelevant in this accident scenario because the worker would not have the knowledge to identify unsafe conditions caused by a human factors violation.

\section{CONCLUSIONS}

This paper has presented ARCTM, which complements construction accident investigation techniques by raising many important questions and possible answers that help identify the root causes behind occupational accidents. ARCTM emphasizes the need to consider worker training, worker attitude, and management procedures when prevention efforts are contemplated.

The accident scenarios analyzed using ARCTM show that the analysis of events - whether they are existing or developing unsafe conditions or unsafe acts, and how workers respond to or are affected by these events - is a logical route to take to accurately determine the root causes of accidents on construction sites. In addition to identifying the root cause(s) of accidents, using ARCTM also provides solutions or possible areas to consider to prevent accident reoccurrence.

ARCTM's philosophy can be summarized into three main points. First, workers who do not have sufficient training or knowledge about their jobs should not be expected to identify all unsafe conditions surrounding their work and avoid the possible accident situations. Second, workers who do have the training or knowledge about their jobs but still decide to work unsafe will never be accident-free unless their attitudes toward safety change. Third, management procedures should be designed to identify and remove unsafe conditions in a proactive manner, and management should always reinforce the value and importance of safety among workers (see Accident No. 1).

ARCTM provides a template for systematically and rapidly determining areas requiring more investigations, so that labor and management may provide more effective measures for preventing accidents. It should be emphasized that the objective of using ARCTM as a complement to the investigation process should not be limited to finding the party responsible for the accident but to use it to help find answers to the questions of why accidents occur in construction and how to prevent their reoccurrences.

\section{APPENDIX. REFERENCES}

Accident prevention, a workers' education manual. (1983). Intemational Labor Organization, Geneva.
Accident facts. (1997). National Safety Council, Itascia, III.

Adams, E. (1976). "Accident catusation and the manigement system." Profi. Safety, 22(10), 26-29

Bird, F. (1974). Management guide to loss control. Institute Press. Atlanta.

Browu, I. D. (1995). "Accicient reporting and analysis." Eva'uauron of humai work, J. R. Wilsin, and E. N Corlett, eus., Taylor \& Francis, London.

Chaffin, D. B., and Andersson, G. B. (1991). Occupational biomechanics. Wiley, New York.

Cooper, K., and Volard, S. V. (1978). "The influence of the individual on industrial accidents." Accident Prevention, Toronto, 15(5), 45-49.

Culver, C., Florczak, G., Casteli, R., Jr., Pelton, G., and Connolly, C. (1990). "Analysis of construction Catalities - The OSHA Data 19851988." Rej., Occupational Sufeiy and Health Administratioui (USHii), U.S. Department of Labor, Washington, D.C.

Culver, C., Marshall, M., and Connolly, C. (1992). "Construction accidents: The workers' compensation data base 1985-1988." Rep., Occupational Safety and Health Administration (OSHA), U.S. Department of Labor, Washington, D.C.

Davies, V. J., and Tomasin, K. (1990). Construction safety handbook. Thomas Telford, London.

DeJoy, D. M. (1990). "Toward a comprehensive human factors model of workplace accident causation."' Profl. Safety, 35(5), 11-16.

Douglas, H., and Crowe, J. (1976). Effective loss prevention. Industrial Accident Prevention Assoc., Toronto.

Dwyer, T., and Raftery, A. E. (1991). "Industrial accidents are produced by social-relations of work-A sociological theory of industrial accidents." Appl. Ergonomics, 22(3), 167-178.

Friend, M. A., and Kohn, J. P. (1992). "A behavioral approach to accident prevention." Occupational Hazards, 54(10), 113-115.

Fullman, J. B. (1984). Construction safety, security, and loss prevention. Wiley, New York.

Goldsmith, D. (1987). Safety management in construction and industry. McGraw-Hill, New York.

Heath, E. D. (1991). "Identifying those worker populations that are at higher levels of risk." Am. Industrial Hygiene Assn. J., 52(4), A211A212.

Heinrich, H. W. (1959). Industrial accident prevention. McGraw-Hill, New York.

Heinrich, H. W., Peterson, D., and Roos, N. (1980). Industrial accident prevention. McGraw-Hill, New York.

Helander, M. G. (1991). "Safety hazards and motivation for safe work in the construction industry." Int. J. Industrial Ergonomics, London, 8(4), 205-223.

Hinze, J. W. (1997). Construction safety. Prentice-Hall, Englewood Cliffs, N.J.

Hoyos, C. G., and Zimolong, B. (1988). Occupational safety and accident prevention, behavioral strategies and methods. Elsevier, Amsterdam.

Kerr, W. (1957). "Complementary theories of safety psychology." J. Social Psychology, 45, 3-9.

Klumb, P. L. (1995). "Cognitive failures and performance differences: Validation studies of a German version of the cognitive failures questionnaire." Ergonomics, 38(7), 1456-1467.

Krause, T. R., Hidley, J. H., and Lareau, W. (1984). "Behavioral science applied to accident prevention." Proff. Safety, 29(7), 21-27.

Krause, T. R., and Russell, L. R. (1994). "The behavior-based approach to proactive accident investigation." Profl. Safety, 39(3), 22-28.

La Bette, C. R. (1990). "Innovative procedures in construction safety." Profl. Safety, 35(4), 35-39.

MacCollum, D. V. (1990). "Time for change in construction safety." Profl. Safety, 35(2), 17-20.

McClay, R. E. (1989). "Toward a more universal model of loss incident causation-Part I." Profl. Safety, 35(1), 15-20.

McClay, R. E. (1989). "Toward a more universal model of loss incident causation-Part II." Profl. Safety, 35(2), 34-39.

Norman, D. A. (1981). "Categorization of action slips." Psychological Rev., 88, 1-14.

Petersen, D. (1971). Techniques of safety management. McGraw-Hill, New York.

Petersen, D. (1975). Safery management-A human approach. Aloray, Englewood, N.J.

Petersen, D. (1982). Human Error-Reduction and Safety Management. STPM Press, New York.

Peyton, R. X., and Rubio, T. C. (1991). Construction safety practices and principles. Van Nostrand Reinhold, New York.

Reason, J. T. (1990). Human error. Cambridge University Press, New York. 
Recht. J. (1970). Systems safety analysis: Error rates and costs. National Sately Council, Chicago.

Rictze, R. B. (1990). "Proactive construction management." Profl. Safety. 35(1), 14-16

Righy. L. V. (1970). "The nature of human error." Proc., Annu. Tech. Cimf. Nians, of the Am. Soc for Quality Control, 4/5-566.

Rook, L., Altman, j., and Swain, A. (1966). Human error quantification.
Sandia Corp., Albuqerque, N.M.

Wagenaar, W. A., Hudson, P. T., and Reason, J. T. (1990). "Cognitive failures and accidents." Appl. Cognitive Psychology, 4, 273294.

Weaver, D. A. (1971), "Symptoms of operational error." Proff. Safety. 17(10), 24-34

Zeller, D. B. (1986). “Heinrich ,evisited," Proft. Safety, 31(10), 40-42. 